\title{
An innovative educational approach to professional development of medical laboratory scientists in Botswana
}

This article was published in the following Dove Press journal:

Advances in Medical Education and Practice

II April 2014

Number of times this article has been viewed

\author{
Mabel KM Magowe' \\ Jenny H Ledikwe 2,3 \\ Ishmael Kasvosve' \\ Robert Martin ${ }^{2}$ \\ Kabo Thankane ${ }^{3}$ \\ Bazghina-werq Semo ${ }^{2,3}$
}

'Faculty of Health Sciences, University of Botswana, Gaborone, Botswana; ${ }^{2}$ Department of Global Health, University of Washington, Seattle, Washington, USA; ${ }^{3}$ Botswana International Training and Education Center for Health, Gaborone, Botswana

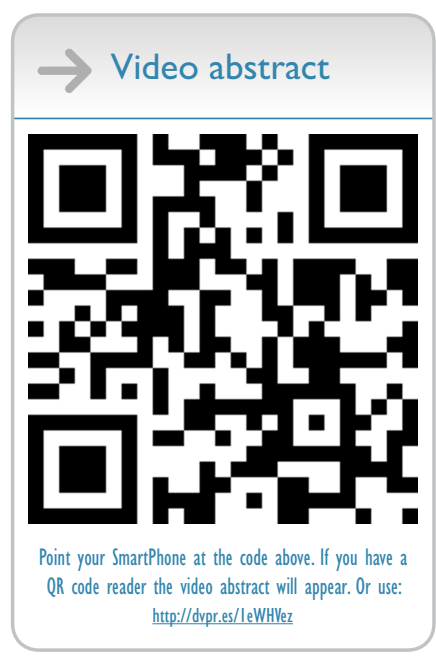

Correspondence: Bazghina-werq Semo PO Box AC46, ACH, Riverwalk, Gaborone, Botswana

$\mathrm{Tel}+2673900925$

Fax +2673900952

Email bazsemo@uw.edu
Purpose: To address the shortage of laboratory scientists in Botswana, an innovative, one-year academic bridging program was initiated at the University of Botswana, to advance diplomaholding laboratory technicians towards becoming laboratory scientists holding Bachelor's degrees. An evaluation was conducted, which described the outcomes of the program and the lessons learned from this novel approach to meeting human resource needs.

Methods: This was a cross-sectional, mixed-methods evaluation. Qualitative interviews were conducted with graduates of the Bachelor of Science (BSc) Medical Laboratory Sciences (MLS) bridging program, along with the graduates' current supervisors, and key informants who were involved in program development or implementation. The quantitative data collected included a written questionnaire, completed by program graduates, with a retrospective pre-test/post-test survey of graduates' confidence, in terms of key laboratory competencies.

Results: The BSc MLS bridging program produced thirty-three laboratory scientists over 3 years. There was a significant increase in confidence among graduates, for specified competencies, after the program $(P<0.05)$. Graduates reported acquiring new skills and, often, accepting new responsibilities at their former workplace, particularly in relationship to leadership and management. Five graduates enrolled in advanced degree programs. Most graduates assumed increased responsibility. However, only two graduates were promoted after completing the training program. The lessons learned include: the importance of stakeholder involvement, the need for data to identify local needs, financial sustainability, catering for the needs of adult learners, and ensuring a technically challenging work environment, conducive to the application of skills learned during training.

Conclusion: A strong public health and clinical laboratory system is essential for the rapid detection and control of emerging health threats, and for patient care. However, there is a need to adequately prepare laboratory human resources, to ensure efficient and effective laboratory services. Advancement of laboratory technicians towards becoming laboratory scientists, through a bridging program, can provide the necessary skills within a short time.

Keywords: human resources for health, medical laboratory science education, bridging program

\section{Introduction}

Worldwide, there is a chronic shortage of trained health workers. ${ }^{1,2}$ Sub-Saharan Africa, with $11 \%$ of the world's population, $25 \%$ of the global burden of disease, and only $3 \%$ of the global health workforce, is among the regions hardest hit by the human resource crisis. ${ }^{2}$ Health workforce shortages in many African countries are further impacted by an imbalanced skill mix and an uneven geographical distribution of health professionals. ${ }^{1,3,4}$ Furthermore, the HIV epidemic has exacerbated 
this situation, due to increased workload and HIV-related deaths among health workers. ${ }^{5}$

Clinical laboratory staffing levels have frequently been reported to be inadequate in resource-constrained settings. ${ }^{6-8}$ For example, data from Tanzania suggest that $80 \%$ of the posts for clinical laboratory assistants will be vacant by 2018 , given current demand and the dearth of adequate training programs. ${ }^{8}$ The lack of human resource capacity is a major challenge, limiting laboratory services in many countries, ${ }^{9}$ particularly with the burdens of tuberculosis, HIV infection, malaria, and other tropical diseases. ${ }^{10}$ Furthermore, the level of technical expertise needed has increased, as the number of diagnostic tests increases, and as sophisticated technologies are introduced to improve disease detection, prevention, and control. ${ }^{9}$

A key contributing factor to laboratory human resource constraints in resource-limited countries is insufficient tertiary education relating to laboratory sciences. ${ }^{10}$ A needs assessment for strengthening laboratory human resource capacity in sub-Saharan Africa highlights the need to strengthen pre-service training. ${ }^{11}$ Limited educational opportunities have been cited as an impediment to the laboratory systems in Tanzania, ${ }^{12}$ Ukraine, ${ }^{13}$ and Botswana. ${ }^{14}$ While educating individuals outside their countries can be part of the solution, attention should be directed towards developing tertiary training programs within resource-limited settings, to minimize costs and maximize output. ${ }^{15}$ Furthermore, given the current demand for skilled laboratory personnel, there is a need for novel training methods, to more rapidly meet staffing requirements. ${ }^{8}$

To address the shortage of laboratory scientists in Botswana, a one-year academic bridging program was initiated at the University of Botswana (UB), to advance diplomalevel laboratory technicians to laboratory scientists with Bachelor of Science (BSc) degrees. A needs assessment was conducted, to inform curriculum development. The degree curriculum was designed to develop skills in clinical laboratory management, laboratory data management, operational research, immunology, and molecular biology techniques, building upon the professional training obtained at diploma level (Table 1). The BSc Medical Laboratory Sciences (MLS) bridging program included 300 hours of lectures, 450 hours of laboratory sessions, and 200 hours of supervised attachment to a molecular diagnostics clinical laboratory. Three years after inception of the program, an evaluation was conducted, with the objective of describing outcomes, in terms of skills and knowledge gained, in addition to how these skills have impacted professional responsibilities.
Table I Summary of courses offered at diploma level, and for completion of the degree program

\begin{tabular}{lll}
\hline & Diploma program & Degree program \\
\hline Duration & 3 years & I year \\
Courses & Mathematics & Cell biology \\
& Physics & Genetics \\
& Chemistry & Biochemistry/microbiology \\
& Environmental health & Molecular biology \\
& Human anatomy and & Virology \\
& physiology & Immunology \\
& Sociology & Molecular diagnostics \\
& Public health & Research methods \\
& Medical microbiology & Introduction to biostatistics \\
& Medical parasitology & Research project \\
& Haematology & Laboratory management \\
& Immunohematology & Attachment to CD4 and \\
& Clinical chemistry & viral load testing \\
& Histology and cytology & laboratories for 5 weeks \\
& Attachment to a hospital & \\
laboratory for I year & \\
\hline
\end{tabular}

\section{Methods}

\section{Evaluation}

This was a cross-sectional, mixed methods evaluation. Qualitative interviews were conducted with graduates of the BSc MLS bridging program, graduates' current supervisors, and key informants (KIs). The quantitative data collected included a written survey completed by program graduates. The evaluation was conducted by the International Training and Education Center for Health (I-TECH) in Botswana, a collaboration between the University of Washington and the University of California, San Francisco. It was approved by the ethical review boards at the UB, Ministry of Health, and University of Washington.

\section{Participants: graduates}

Of the thirty-three individuals who graduated over three years (2010-2012) in the BSc MLS bridging program, two could not be contacted. Of the remaining thirty-one individuals, thirty participated in telephone interviews $(97 \%)$, to explore their perceptions of the program and professional duties after completion of the program. Following the telephone interview, all participants were asked to complete a written questionnaire, comprising a retrospective pre-test and post-test, to measure self-reported confidence in selected competencies before and after the program. This design is recommended to curb responseshift bias and sensitization effects that occur with the traditional pre-test/post-test methodology, and when students' frame of mind changes over time, due to the effects of the 
program. ${ }^{16,17}$ Twenty-three graduates $(74 \%)$ completed the questionnaire.

\section{Participants: supervisors}

At the time of the assessment, twenty supervisors of program graduates were identified. Fifteen of them (75\%), representing thirteen organizations (mainly health facilities), participated in telephone interviews to determine their perceptions of the performance of graduates.

\section{Participants: key informants}

Face-to-face interviews were conducted with KIs, purposefully selected, based on their involvement in the development or implementation of the bridging program. Fourteen of the fifteen (93\%) individuals who were identified participated, representing seven institutions, including the Ministry of Health, the tertiary education sector, donor agencies, technical assistance organizations, regulatory bodies, and facilities serving as clinical laboratory attachment sites. Information was collected on program development and implementation, as well as on successes and challenges.

\section{Data collection and analysis}

Interviews were voice recorded, with permission from respondents, transcribed, and analyzed with ATLAS.ti version 6.0 software (Scientific Software Development GmbH, Berlin, Germany). A general inductive approach was taken. ${ }^{18}$ This involved the coding of textual data and identification of common themes, in order to condense the data into a summary format and establish links with the evaluation objectives, which were to describe the achievements of the UB bridging program and document lessons learned. Survey data were analyzed using PASW Statistics version 20 software, (IBM Corporation, Armonk, NY, USA). Data were summarized using descriptive statistics. The Wilcoxon signed-rank test was used to compare graduates' ratings of their level of confidence within selected competencies, before and after the course.

\section{Results \\ Development of the BSc MLS bridging program}

KIs explained that the program emerged from a need to rapidly increase the number of medical laboratory scientists in Botswana. They indicated that, prior to initiation of the bridging program, local laboratory scientists had been trained abroad, which was resource intensive and produced relatively few graduates. Interviewees stated that it would take approximately 6 years to graduate the first cohort from a traditional BSc program, given the time required for curriculum development, plus 4 years for students to complete program requirements. The BSc MLS bridging program was created to advance existing laboratory technicians to BSc degree level in a shorter period of time. As stated by KIs:

With HIV/AIDS, there was increasing complexity in laboratory testing procedures, such as CD4, viral load testing, etc. The available pool of diploma-level lab technicians did not have adequate skills to service the system fully.

The method [training outside Botswana] by which the lab scientists were being trained before was not actually yielding much. Occasionally, it would yield four a year at the most. Another challenge was the expenses involved, because people needed to be transferred out [of the country] to other universities that were offering degree[s] in medical laboratory science.

It happened quickly. If you have a dire need for human resource training, you do not need to wait to put in a 4-year program.

A wide group of stakeholders supported the development and implementation of the program, including the Ministry of Health, local tertiary education institutions, funders, development partners, and local regulatory bodies. In consultation with external universities, stakeholders reviewed the curriculum for the local medical laboratory technician diploma program, to determine the content needed to advance laboratory technicians to degree level. The content was drafted by stakeholders and approved by the local regulatory authority. One KI explained:

After agreeing on the needed competencies, we drafted the curriculum. The document was then passed on to the Botswana Health Professions Council for registrability of graduates, and it approved the content.

During the first year of the program, student selection was based mostly on seniority. These candidates were not necessarily the best, as evidenced by the high failure rate (67\%) of the first group. Subsequently, UB admitted only those who qualified on merit.

We had a [high] failure rate in the first year, because the demands of the course were too high for the students. We improved by tightening the minimum [acceptance] criteria.

\section{Program participants and outcomes}

In total, thirty-three medical laboratory scientists graduated through the program over 3 years. Table 2 presents 
Table 2 Characteristics of program graduates who responded to the survey $(\mathrm{N}=23)$

\begin{tabular}{|c|c|c|}
\hline Participant characteristic & $\begin{array}{l}\text { Frequency } \\
\text { (N) }\end{array}$ & $\begin{array}{l}\text { Percentage } \\
\text { (\%) }\end{array}$ \\
\hline \multicolumn{3}{|l|}{ Sex } \\
\hline Male & 10 & 43.5 \\
\hline Female & 13 & 56.5 \\
\hline \multicolumn{3}{|l|}{ Age (years) } \\
\hline$\leq 30$ & 4 & 17.4 \\
\hline $31-40$ & 12 & 52.2 \\
\hline $4 I-50$ & 7 & 30.4 \\
\hline \multicolumn{3}{|c|}{ Work experience prior to program enrollment (years) } \\
\hline $0-5$ & 4 & 17.4 \\
\hline $6-10$ & 8 & 34.8 \\
\hline $11-15$ & 8 & 34.8 \\
\hline $16-20$ & 3 & 13.0 \\
\hline \multicolumn{3}{|l|}{ Year enrolled in program } \\
\hline 2009 & 6 & 26.1 \\
\hline 2010 & 14 & 60.9 \\
\hline 2011 & 3 & 13.0 \\
\hline \multicolumn{3}{|l|}{ Year completed program } \\
\hline 2010 & 2 & 8.7 \\
\hline 2011 & 17 & 73.9 \\
\hline 2012 & 4 & 17.4 \\
\hline
\end{tabular}

demographic characteristics of the twenty-three graduates who responded to the written survey. The majority were female $(\mathrm{N}=13 ; 57 \%)$, aged $31-40$ years $(\mathrm{N}=12 ; 52 \%)$. Almost two-thirds of the respondents $(\mathrm{N}=14 ; 61 \%)$ joined the program in 2010, during its second year. Most had more than 5 years of previous work experience.

The survey data suggest that graduates $(70 \%)$ generally felt that the BSc MLS bridging program had prepared them for new responsibilities. They rated their perceived level of confidence in specified competencies before and after the program on a scale of 1 (not at all confident) to 4 (very confident) (Table 3$)$. A significant increase $(P<0.05)$ in confidence for all competencies was measured. The competency area in which graduates reported the highest mean confidence level was CD4 enumeration and HIV diagnosis and monitoring (3.8 \pm 0.4 ), followed by quality management

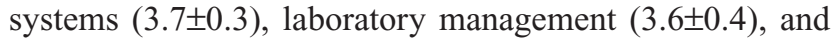
operations research $(3.5 \pm 0.4)$. The largest increase in confidence score from before to after the program was found for operations research, in which median scores increased from 2.0 to 3.3 .

Graduates' perceptions of the program were positive. During telephone interviews, many said they were satisfied with the course content and teaching methods. Additionally, graduates indicated that they appreciated the exposure to management and research content, and they said the internship was also a useful part of the program. As stated by one graduate:

The course content was very relevant to us, focusing on laboratory testing and molecular biology. For courses like biochemistry, which were general, the lecturer always tried to cater for us, knowing that we are from the clinical background. He gave examples which related to us.

Data from the written survey indicated that after completing the BSc MLS bridging program, most graduates $(73.9 \%)$ returned to work at the same facility where they had been employed prior to enrollment in the program, and they reported they had taken on a higher level of responsibility.

Now I am a quality assurance officer in our lab.

Two supervisors reported the following about two program graduates:

I have appointed one [bridging program graduate] to be a quality manager [...] when she came back from school, and she is doing well. She is now also supervising a number of others.

When I compare his skills and knowledge before and after the program, there is a difference, especially in management and supervision. He also has more knowledge than before. He operates at a higher level.

Several of the program graduates indicated that they had applied and been selected to pursue a Master's degrees in the field of laboratory sciences, with the hope that they would take up faculty positions at UB. KIs stated:

Out of the pool that has been trained, the University of Botswana has recruited five [program graduates]. So, UB has directly benefitted, because these are the ones that we are now developing to become lecturers, to come and teach in this new program.

Two of them [the graduates] have finished their Masters and now they have started their $\mathrm{PhD}$ studies.

We were very excited when some of the students who came out of this program were able to apply in UK, US and [...] Australia, and be accepted to a Master's program. It is evidence that your program is strong.

Even though graduates commonly reported taking on additional responsibilities, only two $(8.7 \%)$ of the program graduates indicated in the written survey that they had been 
Table 3 Comparison of self-reported confidence (related to key laboratory competencies) from survey respondents ( $\mathrm{N}=23$ ), before and after the UB BSc MLS Bridging Program*

\begin{tabular}{|c|c|c|c|c|c|c|}
\hline \multirow[t]{2}{*}{ Bridging program competency } & \multirow[t]{2}{*}{$\mathbf{N}$} & \multicolumn{2}{|c|}{ Mean \pm SD } & \multicolumn{2}{|c|}{ Median rating } & \multirow[t]{2}{*}{$P$-value } \\
\hline & & Before & After & Before & After & \\
\hline \multicolumn{7}{|l|}{ Laboratory management } \\
\hline Applying principles of management and safety & 23 & $2.4 \pm 1.1$ & $3.5 \pm 0.7$ & 2 & 4 & 0.0001 \\
\hline $\begin{array}{l}\text { Exercising principles of logistic management to ensure uninterrupted } \\
\text { testing in the laboratory }\end{array}$ & 22 & $2.6 \pm 1.0$ & $3.6 \pm 0.6$ & 3 & 4 & 0.0001 \\
\hline Performing supervisory responsibilities & 22 & $2.8 \pm 0.9$ & $3.5 \pm 0.6$ & 3 & 4 & 0.002 \\
\hline Providing leadership in area of responsibility & 23 & $2.5 \pm 0.8$ & $3.5 \pm 0.7$ & 3 & 4 & 0.0001 \\
\hline Applying problem solving skills/tasks & 23 & $2.5 \pm 0.7$ & $3.5 \pm 0.6$ & 3 & 4 & 0.0001 \\
\hline $\begin{array}{l}\text { Demonstrating professional conduct when interacting with clients } \\
\text { and peers }\end{array}$ & 23 & $3.2 \pm 0.8$ & $3.9 \pm 0.3$ & 3 & 4 & 0.001 \\
\hline Applying adult learning principles & 13 & $2.8 \pm 0.8$ & $3.7 \pm 0.6$ & 3 & 4 & 0.003 \\
\hline Applying principles of laboratory information management systems & 21 & $2.5 \pm 1.0$ & $3.5 \pm 0.7$ & 3 & 4 & 0.0001 \\
\hline Summary score & & $2.7 \pm 0.7$ & $3.6 \pm 0.4$ & 2.6 & 3.6 & 0.0001 \\
\hline \multicolumn{7}{|l|}{ Quality management systems in the clinical laboratory } \\
\hline Knowledge and application of principles of QSE & 21 & $2.5 \pm 1.0$ & $3.6 \pm 0.7$ & 3 & 4 & 0.0001 \\
\hline Relating to QSE, ISO, and CLS standards & 22 & $2.5 \pm 0.9$ & $3.5 \pm 0.6$ & 3 & 4 & 0.002 \\
\hline $\begin{array}{l}\text { Writing standard operating procedures using internationally } \\
\text { recognized formats }\end{array}$ & 21 & $2.6 \pm 0.9$ & $3.5 \pm 0.7$ & 3 & 4 & 0.001 \\
\hline Describing elements of preventive maintenance of laboratory equipment & 21 & $3.0 \pm 0.7$ & $3.7 \pm 0.5$ & 3 & 4 & 0.001 \\
\hline $\begin{array}{l}\text { Evaluating, selecting, and writing specifications for purchase of new } \\
\text { laboratory equipment }\end{array}$ & 15 & $2.5 \pm 0.9$ & $3.3 \pm 0.7$ & 3 & 3 & 0.002 \\
\hline Developing inventory control plan for laboratory supplies and reagents & 21 & $2.9 \pm 1.0$ & $3.7 \pm 0.6$ & 3 & 4 & 0.001 \\
\hline $\begin{array}{l}\text { Identifying laboratory monitoring tools necessary to monitor } \\
\text { laboratory processes so that problems can be identified and corrected }\end{array}$ & 19 & $2.8 \pm 0.6$ & $3.7 \pm 0.5$ & 3 & 4 & 0.0001 \\
\hline $\begin{array}{l}\text { Understanding and ability to differentiate between quality } \\
\text { assurance and quality control }\end{array}$ & 22 & $2.9 \pm 0.8$ & $3.8 \pm 0.5$ & 3 & 4 & 0.0001 \\
\hline $\begin{array}{l}\text { Making decisions based on results of proficiency testing (external } \\
\text { quality assurance) and put in measures to prevent and remedy } \\
\text { testing errors }\end{array}$ & 21 & $2.8 \pm 0.9$ & $3.6 \pm 0.6$ & 3 & 4 & 0.0001 \\
\hline $\begin{array}{l}\text { Describing both personal protective equipment required for safe } \\
\text { laboratory use and understanding the concept of universal precautions }\end{array}$ & 22 & $3.3 \pm 0.6$ & $3.9 \pm 0.3$ & 3 & 4 & 0.0001 \\
\hline $\begin{array}{l}\text { Describing the importance of maintaining sample integrity, and } \\
\text { assuring that all regulations and requirements are met when } \\
\text { transporting samples }\end{array}$ & 22 & $3.3 \pm 0.8$ & $3.9 \pm 0.2$ & 3 & 4 & 0.001 \\
\hline $\begin{array}{l}\text { Describing and applying essential components of documentation } \\
\text { with an information management system (paper or electronic) }\end{array}$ & 21 & $2.9 \pm 0.8$ & $3.8 \pm 0.5$ & 3 & 4 & 0.001 \\
\hline $\begin{array}{l}\text { Awareness of the importance of developing interpersonal skills } \\
\text { coupled with understanding of how quality management } \\
\text { processes help laboratory in order to meet customer needs }\end{array}$ & 22 & $2.7 \pm 0.8$ & $3.7 \pm 0.5$ & 3 & 4 & 0.0001 \\
\hline $\begin{array}{l}\text { Developing and performing preventive and corrective maintenance } \\
\text { of testing equipment in the laboratory }\end{array}$ & 22 & $3.1 \pm 0.6$ & $3.7 \pm 0.5$ & 3 & 4 & 0.001 \\
\hline $\begin{array}{l}\text { Evaluating and selecting the equipment and methods based on } \\
\text { needs of the laboratory and budgetary resources }\end{array}$ & 11 & $2.5 \pm 0.7$ & $3.7 \pm 1.2$ & 3 & 3.5 & 0.014 \\
\hline $\begin{array}{l}\text { Verifying quality control procedures and developing solutions } \\
\text { to maintain accuracy and precision of test results }\end{array}$ & 17 & $2.8 \pm 0.9$ & $3.4 \pm 0.7$ & 3 & 3.5 & 0.013 \\
\hline Summary score & & $2.8 \pm 0.5$ & $3.7 \pm 0.3$ & 2.9 & 3.7 & 0.0001 \\
\hline CD4 enumeration and HIV diagnosis and monitoring & & & & & & \\
\hline $\begin{array}{l}\text { Performing HIV DNA tests and viral load assays and interpreting } \\
\text { the results }\end{array}$ & 17 & $2.3 \pm 1.2$ & $3.9 \pm 0.3$ & 2 & 4 & 0.002 \\
\hline Performing CD4 enumeration and interpreting the results & 19 & $2.9 \pm 0.8$ & $3.8 \pm 0.4$ & 3 & 4 & 0.001 \\
\hline $\begin{array}{l}\text { Maintaining, operating, and troubleshooting equipment used in HIV } \\
\text { viral load testing and CD4 enumeration }\end{array}$ & 18 & $2.8 \pm 1.0$ & $3.6 \pm 0.6$ & 3 & 4 & 0.004 \\
\hline $\begin{array}{l}\text { Reviewing HIV viral load and HIV DNA quality control and patient } \\
\text { results and identifying discrepancies }\end{array}$ & 17 & $2.5 \pm 1.0$ & $3.7 \pm 0.6$ & 3 & 4 & 0.001 \\
\hline
\end{tabular}


Table 3 (Continued)

\begin{tabular}{|c|c|c|c|c|c|c|}
\hline \multirow[t]{2}{*}{ Bridging program competency } & \multirow[t]{2}{*}{$\mathbf{N}$} & \multicolumn{2}{|c|}{ Mean \pm SD } & \multicolumn{2}{|c|}{ Median rating } & \multirow[t]{2}{*}{$P$ P-value } \\
\hline & & Before & After & Before & After & \\
\hline Authorizing release of HIV viral load and CD4 results & 19 & $2.6 \pm 1.1$ & $3.8 \pm 0.4$ & 3.0 & 4.0 & 0.001 \\
\hline Summary score & & $2.7 \pm 0.9$ & $3.8 \pm 0.4$ & 3.0 & 4.0 & 0.001 \\
\hline \multicolumn{7}{|l|}{ Operations research } \\
\hline $\begin{array}{l}\text { Identifying gaps/problems in testing and formulating a testable } \\
\text { hypothesis to investigate the problem }\end{array}$ & 17 & $2.1 \pm 0.9$ & $3.6 \pm 0.5$ & 2.0 & 4.0 & 0.001 \\
\hline Designing evaluation research to investigate a problem & 18 & $2.2 \pm 1.0$ & $3.4 \pm 0.5$ & 2.0 & 3.0 & 0.001 \\
\hline $\begin{array}{l}\text { Collecting and analyzing data and drawing valid conclusions that } \\
\text { can be used to improve testing in a clinical laboratory }\end{array}$ & 19 & $2.2 \pm 0.9$ & $3.5 \pm 0.6$ & 2.0 & 4.0 & 0.0001 \\
\hline Summary score & & $2.2 \pm 0.9$ & $3.5 \pm 0.4$ & 2.0 & 3.3 & 0.0001 \\
\hline
\end{tabular}

formally promoted. Some graduates were demotivated by the lack of promotion. One graduate said:

I am not sure if it is worth it to go for further studies. We are sent to further our studies and when we return with extra knowledge, there will be no promotion. I completed in 2010 and, up to now, I am just like those who have never gone anywhere.

\section{Lessons learned}

The development and implementation of the BSc MLS bridging program provided many lessons that could guide other academic institutions in resource-limited settings for developing similar programs. These lessons included the importance of stakeholder involvement, meeting local healthcare needs, financial sustainability of the program, catering to the needs of adult learners, and ensuring a technically challenging work environment after training.

\section{Multiple stakeholders should be involved in program development to ensure effectiveness}

KIs reported that the involvement of multiple stakeholders was a key success factor in the development and implementation of the bridging program. From the beginning, it was important to identify and seek guidance from stakeholders' with different areas of expertise. One KI said:

This was a consultative process. When you engage together, you find out who is the expert in what area [...] to give us the guidance in whatever part of the program we were considering at that time.

All the stakeholders were involved. What you want is credibility for your qualification. You want your students, to be able to be recognized for the skills they have acquired, because that increases their job opportunities in the market. So bringing all stakeholders on board and involving them helped bring credibility to our program.

\section{Program development should be guided by data to ensure local needs are met}

An extensive assessment was conducted to identify the knowledge and skills needed locally by laboratory scientists. This was important in identifying gaps in content needed to supplement the diploma-level program, and to ensure that program graduates were able to meet the needs of laboratory systems in the settings they work in. The assessment's findings highlighted the need to include leadership and management courses in the program. KIs mentioned:

[The program] had to be relevant and need-based. Are the competencies meeting the needs on the ground?

We started with the [diploma-level] curriculum [...] we identified the missing parts that we needed to add.

\section{Financial resources need to be adequate for program success}

One KI acknowledged that the sustainability of the program relied upon funding for the candidates and for the program. During the first year of the program, donor funding helped ensure that enrollment was high. However, in subsequent years, there was insufficient funding to enroll the maximum number of students. As stated by KIs:

UB had developed the capacity to train twenty students per year, and these slots were available, they were not all utilized [...] because the Ministry [of Health] could just not raise the money for study leave for their officers to come for training. 
When one is thinking of instituting a new program or a new initiative, it is important to look for funding over several years.

\section{Bridging programs should ensure the unique needs of adult learners are met}

Prior to entering the bridging program, students had completed a diploma-level academic program and been employed as laboratory technicians. During the telephone interview, some graduates indicated that they were initially challenged by returning to an academic environment. A graduate and a $\mathrm{KI}$, respectively, stated:

For ten years I was working. All of a sudden, I go back to school and it is the final year. You try to rewind 10 years back on the molecular chemistry and biochemistry that you did way back.

We probably should have had some kind of a pre-entry science courses or given them a short course to bring people who had been in the field back to academics.

\section{Progression in technical duties after a bridging program is critical in strengthening laboratory systems}

After completion of the bridging program, it is important for graduates to be afforded new responsibilities. While most reported taking on new supervision and management duties after the program, some were disappointed that their technical duties did not necessarily become more complex. Interviews with the graduates suggested that those who had moved to different laboratories were generally more likely to report taking more professionally complex tasks than those who returned to the same facility. As stated by graduates:

We are still doing the same work because we are limited by resources. So it doesn't matter if you are a technician or scientist.

Since I have been transferred $[\ldots]$ the work is a bit more complex.

\section{Discussion}

The BSc MLS bridging program produced thirty-three laboratory scientists over 3 years. Previously, when the training was done abroad, the country was only able to train 0-3 laboratory scientists per year (Motswaledi MS, Deputy Director Clinical Services, Ministry of Health, Oral communication, 2007). The graduates acquired new skills through the program and, upon completion of the program, could competently perform HIV viral load testing and CD4 enumerations, without supervision (Table 3). The degreequalified laboratory scientists had not conducted testing in these areas before enrolling for the program. The graduates conducted individual research projects under faculty supervision, and felt confident in undertaking management responsibilities on return to their workplace. Some graduates also took on new responsibilities at their former place of employment, particularly in leadership and management.

On completion of the degree program, other graduates enrolled in advanced degree programs, and the majority of them were recruited by the University of Botswana to increase its capacity to train more degree-qualified medical laboratory scientists. The program was hailed by KIs, graduates, and supervisors as successful, in terms of producing local laboratory scientists in a relatively short time.

Bridging programs have been successfully implemented in health sciences, particularly in the field of nursing. ${ }^{19}$ Such programs are designed to develop skills and educationally prepare health professionals to practice at a higher skill level. A bridging program for dental therapists in Australia was found to be effective for extending their scope of practice to include management of adult patients. ${ }^{20}$ Data from the present evaluation provide evidence that bridging programs can play an important role in meeting human resource needs related to laboratory scientists.

Training of skilled laboratory staff has been documented as a challenge facing laboratory systems in resource-limited countries. However, with the successful development of human resources in public health, it is important that attention be given to retaining these skilled laboratory staff. "Brain drain" is the phenomenon of highly-skilled professionals leaving resourcelimited settings to seek better professional opportunities and pay; it has been cited as an impediment to maintaining quality laboratory systems in resource-constrained countries. ${ }^{15}$ It has been reported that approximately $90 \%$ of laboratory staff in Tanzania leave public service to join other employers within the country. ${ }^{11}$ Recommendations of the World Health Organization (WHO) emphasize that retaining, and retraining of, the health workforce is particularly relevant. ${ }^{21}$ Attention to career progression has been noted by others as important in developing a sustainable cadre of laboratory personnel. ${ }^{10}$

WHO also emphasized the importance of continuing professional development for laboratory staff. ${ }^{1}$ Countries developing new training programs will need to ensure there is adequate in-service training to enable program graduates to remain up-to-date with rapid changes in diagnostic technology and the development of increasingly advanced equipment. In addition to the factors mentioned above, 
highly-skilled staff, such as laboratory scientists, are often unwilling to work within public health systems, due to low salary structures within the public sector. ${ }^{9}$ Attention to these factors is critical, in order to retain these skilled workers.

A limitation of this evaluation was the potential for social desirability, as KIs participated in the development and implementation of the bridging program. However, this was balanced with interviews with graduates and their supervisors. Additionally, using a retrospective pre-test/ post-test design to measure change in student confidence of key laboratory competencies can lead to confounding factors related to recall bias. However, several studies suggest that this design may be more accurate than a traditional pre-test/ post-test approach. ${ }^{16,17}$ Additional research, assessing work performance of the graduates, is warranted.

\section{Conclusion}

A strong national clinical laboratory system is critical for responding effectively; to rapidly detect and control emerging global health threats, including HIV and many other diseases. There is a clear need for skilled health workers to ensure that laboratory systems operate efficiently and effectively. This evaluation has demonstrated that involvement of key stakeholders, and partnership between training institutions and the service, was essential in the successful implementation of the program. Recognition of prior learning experience, and determining the skills gap between laboratory technicians and laboratory scientists, informed the content of the curriculum and the duration of the program. This evaluation has also demonstrated that upgrading laboratory technicians to medical laboratory scientists, locally, through a bridging program, was successful in providing the necessary skills within a shorter time than through traditional, 4-year programs.

\section{Acknowledgments}

This work was supported by the President's Emergency Plan for AIDS Relief (PEPFAR), through funding to the University of Washington and I-TECH from the US Department of Health and Human Services, Health Resources and Services Administration (HRSA) Global HIV/AIDS Bureau, Cooperative Agreement \# U91HA06801, and the Afya Bora Consortium Fellowship in Global Health Leadership supported by NIH Office of AIDS Research and CDC/PEPFAR, grant \# U91HA06801B.

\section{Disclosure}

The authors report no conflicts of interest in this work.

\section{References}

1. World Health Organization (WHO). Transformative scale up of health professional education: an effort to increase the numbers of health professionals and to strengthen their impact of health populations. Geneva, Switzerland: WHO; 2011. WHO/HSS/HRH/HEP/2011.01.

2. World Health Organization (WHO). The World Health Report 2006: Working Together for Health. Geneva, Switzerland: WHO; 2006.

3. Anyangwe SC, Mtonga C. Inequities in the global health workforce: the greatest impediment to health in sub-Saharan Africa. Int $J$ Environ Res Public Health. 2007;4(2):93-100.

4. Connell J, Zurn P, Stilwell B, Awases M, Braichet JM. Sub-Saharan Africa: beyond the health worker migration crisis? Soc Sci Med. 2007; 64(9):1876-1891.

5. Chen L, Evans T, Anand S, et al. Human resources for health: overcoming the crisis. Lancet. 2004;364(9449):1984-1990.

6. Martin R, Hearn TL, Ridderhof JC, Demby A. Implementation of a quality systems approach for laboratory practice in resource-constrained countries. AIDS. 2005;19 Supp1 2:S59-S65.

7. Nkengasong JN, Nsubuga P, Nwanyanwu O, et al. Laboratory systems and services are critical in global health: time to end the neglect? $\mathrm{Am}$ J Clin Pathol. 2010;134(3):368-373.

8. International Training and Education Center for Health (I-TECH). Scaling Up Human Resources for Health: A Situational Analysis of Three Potential and Two Existing Laboratory Training Centers in Tanzania. Dar es Salaam, Tanzania: I-TECH; 2010.

9. Ridderhof JC, van Deun A, Kam KM, Narayanan PR, Aziz MA. Roles of laboratories and laboratory systems in effective tuberculosis programmes. Bull World Health Organ. 2007;85(5): 354-359.

10. Birx D, de Souza M, Nkengasong JN. Laboratory challenges in the scaling up of HIV, TB, and malaria programs: The interaction of health and laboratory systems, clinical research, and service delivery. $\mathrm{Am} J$ Clin Pathol. 2009;131(6):849-851.

11. World Health Organization (WHO). Needs Assessment for Strengthening Laboratory Human Resources Capacity for Universal Access to HIV, Malaria and TB Services in Three Sub-Saharan Countries. Geneva, Switzerland: WHO; 2010

12. Mmbuji P, Mukanga D, Mghamba J, et al. The Tanzania Field Epidemiology and Laboratory Training Program: building and transforming the public health workforce. Pan Afr Med J. 2011;10 Supp 1:9.

13. Beregova $\mathrm{O}$. The state and the problems of the education in the sphere of clinical laboratory diagnostics in Ukraine. Biochem Med (Zagreb). 2011;21(1):38-42.

14. Ministry of Health. Integrated Health Service Plan. A strategy for Changing the Health Sector for a Healthy Botswana 2010-2020. Botswana: Ministry of Health; 2010.

15. Martin R, Barnhart S. Global laboratory systems development: needs and approaches. Infect Dis Clin North Am. 2011;25(3): 677-691, x.

16. Bhanji F, Gottesman R, de Grave W, Steinert Y, Winer LR. The retrospective pre-post: a practical method to evaluate learning from an educational program. Acad Emerg Med. 2012;19(2):189-194.

17. Drennan J. Masters in nursing degrees: an evaluation of management and leadership outcomes using a retrospective pre-test design. J Nurs Manag. 2012;20(1):102-112.

18. Thomas DR. A general inductive approach for analyzing qualitative evaluation data. Am J Eval. 2006;27(2):237-246.

19. Babbo G, Fought S, Holk M, Mulligan AM, Perrone C. RN-to-BSN programs in the community college setting: challenges and successes. J Nurs Educ. 2013;52(2):85-90.

20. Calache H, Hopcraft MS. Evaluation of a pilot bridging program to enable Australian dental therapists to treat adult patients. J Dent Educ. 2011;75(9):1208-1217.

21. World Health Organization (WHO). Task Shifting: Global Recommendations and Guidelines. Geneva, Switzerland: WHO; 2008. 
Advances in Medical Education and Practice

Dovepress

\section{Publish your work in this journal}

Advances in Medical Education and Practice is an international, peerreviewed, open access journal that aims to present and publish research on Medical Education covering medical, dental, nursing and allied health care professional education. The journal covers undergraduate education, postgraduate training and continuing medical education including emerging trends and innovative models linking education, research, and health care services. The manuscript management system is completely online and includes a very quick and fair peer-review system. Visit http://www.dovepress.com/testimonials.php to read real quotes from published authors.

Submit your manuscript here: http://www.dovepress.com/advances-in-medical-education-and-practice-journal 